ADHD endophenotypes in a Caribbean Community

Cervantes-Henríquez, M. L., Acosta-López, J. E., Martínez-Banfi, M. L., Vélez, J. I., MejíaSegura, E., Lozano-Gutiérrez, S. G., Sánchez-Rojas M., Zurbarán M. A, Zurek E. E., ArcosBurgos M., Pineda, D. A. \& Puentes-Rozo1 P. J. (2018). ADHD Endophenotypes in Caribbean Families. Journal of attention disorders, 1087054718763741.

\title{
6 INTRODUCTION
}

7 Attention deficit/hyperactivity disorder (ADHD, OMIM 143465) is a phenotypically complex(Acosta, 8 Arcos-Burgos, \& Muenke, 2004) and highly prevalent neurodevelopmental disorder that affects 102012; Jain et al., 2011; Pelham \& Fabiano, 2008; Visser, Bitsko, Danielson, \& Perou, 2010) and frequently persisting into adulthood.(Sibley et al., 2012) Heritability estimates indicate that ADHD symptoms are highly heritable $\left(h^{2}=0.85-0.90\right),($ Rhee, Waldman, Hay, \& Levy, 1999) and that offspring of ADHD affected individuals are six to eight times more likely to develop the condition than those of unaffected individuals.(Biederman \& Faraone, 2005) Studies that have ascertained nuclear, extended, and multigenerational families from ADHD affected probands, and clustering several ADHD affected family members, demonstrated that families are an effective resource to define the genetic basis of ADHD.(Arcos-Burgos et al., 2002; Cannon, Gasperoni, van Erp, \& Rosso, 2001; Castellanos \&

Tannock, 2002) Lewis, 1966) and introduced to psychiatry by Gottesman \& Shields in 1967.(Gottesman \& Shields, 1967) In complex neuropsychiatric conditions such as ADHD, endophenotypes might be defined as 
ADHD endophenotypes in a Caribbean Community

neuropsychological, behavioural, cognitive or neuroanatomical quantitative "measurable components" associated/correlated with the disorder(Castellanos \& Tannock, 2002; Miller \& Rockstroh, 2016; Walters \& Owen, 2007) that occur at a higher frequency in individuals with the disease than in the general population, are heritable, state-independent (that is, manifest in individuals whether the illness is active), tend to co-segregate with the illness within families, and lie in the causal pathway between gene and disease.(Flint \& Munafo, 2007; Lee Gregory, Burton, Shapiro, Rowland, \& Coyle, 2015; Walters \& Owen, 2007) Given that endophenotypes are in general continuous variables instead of categorical traits, do not depend of the inherent difficulties of a symptoms-based clinical diagnosis, and have the ability to differentiate between potential diagnoses that present with similar symptoms,(Brotman et al., 2008; Gottesman \& Gould, 2003) it has been hypothesised that they are well suited to study the genetic and neurophysiological basis of psychiatric traits such as ADHD.(Castellanos \& Tannock, 2002; Mastronardi et al., 2016; Pineda et al., 2011; Sibley et al.) Several ADHD studies have identified potential cognitive endophenotypes in neuropsychological tasks such as continuous vigilance, inhibitory control, alteration of temporal perception, delay aversion, working memory alterations, interval timing deficits, fluid intelligence to sustained attention and visual-motor skills.(Acosta-López et al., 2010; Castellanos \& Tannock, 2002; Henriquez-Henriquez et al., 2014; Pironti et al., 2014)'(Hwang-Gu \& Gau, 2015)'(Mastronardi et al., 2016) Recently, we and others have identified ADHD endophenotypes in families ascertained from two well characterized genetic isolates, the Paisa community in Antioquia, Colombia,(Mastronardi et al., 2016)'(Pineda et al., 2011) and the Central Valley in Costa Rica.(Peskin et al., 2015)'(Arcos-Burgos \& 
ADHD endophenotypes in a Caribbean Community

42 Muenke, 2002) In these studies, several measures of cognitive intelligence, attention, visual and motor 43 skills, verbal coefficient, sustained visual attention, and visuospatial problem resolution reported high 44 heritability values and strong association to the ADHD status.(Pineda et al., 2011),(Peskin et al., 2015) These initial findings support and confirm both: the heterogeneity and complexity of ADHD, as a syndrome and from the cognitive point of view,(Acosta et al., 2004),(Pennington, 2006; E. J. SonugaBarke, Sergeant, Nigg, \& Willcutt, 2008; Willcutt, Pennington, et al., 2010) and the important role that genetic factors play in the aetiology of this neuropsychiatric condition.(Mastronardi et al., 2016)'(Barkley., 1997; Doyle et al., 2005; Nigg, 2001; Willcutt, Betjemann, et al., 2010; Willcutt,

50 Pennington, et al., 2010) heterogeneous as well as it is the cultural heritage.(Sibley et al.) It is well known that Colombia was colonized by Spaniards with variable geographical proportions of genetic admixture with the aboriginal Amerindian populations. This racial and genetic conundrum was later convoluted by the arrival of African populations as consequence of the slaves trading. The racial admixture in Colombia was more pronounced in communities inhabiting the Caribbean coast that had a strong influx of African populations arriving to Cartagena, one of the main trade centres of slaves.(Sibley et al.; Villalón, 2008)

58 Further, earlier in the XX century, the arrival of Arabian populations to the Caribbean brought more diversity to these communities' gene pool. Thus, this differential pattern of admixture that happens in the Colombian Caribbean coast shaped the culture and genetic population structure in a particular and 
61 differential way when compared to other regions of the country.(Barragán-Duarte, 2007; Sibley et al.;

62 Villalón, 2008).

63 In this study, we explored the definition of ADHD cognitive endophenotypes in a family-based 64 sample of 408 individuals ascertained from a community inhabiting the city of Barranquilla, Colombia.

65 With a population of $\sim 2.4$ million where many populations that settled the Atlantic coast

66 converge,(Villalón, 2008) Barranquilla is the biggest city in the Colombian Caribbean coast. Our

67 overarching hypothesis was that there were racial and community specific endophenotypes able to represent a significant variance of the ADHD symptomatology and subtypes, and of the genetics 69 underpinning ADHD susceptibility. 
ADHD endophenotypes in a Caribbean Community

\section{SUBJECTS AND METHODS}

\section{Subjects}

72 Four-hundred and eight individuals belonging to 120 nuclear families from Barranquilla, Colombia and its metropolitan area, with at least a single ADHD affected individual, were recruited in this study. Barranquilla is a modern city of $\sim 2.4$ million people located in the Atlántico state, at the northern Caribbean coast. The Barranquilla population is the result of a racial admixture between Aboriginal Amerindian communities with Spaniards and Africans, and later with other communities (i.e., SyrianLebanese, Sephardi Jews, Germans, Italians and Britons). (Villalón, 2008) Most of the families belonged to medium socioeconomic stratum with an average monthly family income of $\sim$ US $\$ 1,000$ 3,000. All individuals in this study participated voluntarily and provided informed written consent either directly or from their parents (in the case of children; <18 years old). This study was approved by

81 The Ethics Committee of Universidad Simón Bolívar at Barranquilla, Colombia (approval \# 00032 of

82 October 13, 2011).

\section{Clinical assessment}

\section{ADHD diagnosis}

The Diagnostic Interview for Children and Adolescents version IV (DICA-IV)(Palacio et al., 2004;

86 Reich, 2000) was used as the Gold Standard to assess the ADHD diagnosis in children and adults. This

87 interview gathers information about patients from a systematic examination of symptoms, making use

88 of a binary classification system of symptoms $(0=$ absence; $1=$ presence $)$ to explore the commencement and end of them to allow an optimal clinical evaluation. Among others, the DICA-IV 
ADHD endophenotypes in a Caribbean Community

cover childhood disorders, mood, anxiety, nutritional behaviour, psychotic disorders, and psychosocial stress -in conjunction, these areas allow the identification of ADHD and its inattentive, hyperactive and inattentive/hyperactive (combined) subtypes. In the case of children and adolescents, the DICA-IV structure interview was completed by children's parents who reported children's symptoms and consequences in the academic, legal and work-related areas, as well as alcohol and tobacco consumption and its consequences.(Palacio et al., 2004; Reich, 2000; Tacchini, Coppola, Musazzi, Altamura, \& Invernizzi, 1994) This information was subsequently used to define the index case (proband). Presumptive ADHD diagnosis in children was assessed DICA-IV with a self-report evaluating, retrospectively, parents' behaviour during grades 1 to 11.(Acosta-Lopez et al., 2013) Persistent symptoms impacting family, social and work-related environments were also recorded. The DICA-IV interview has successfully been used in Colombia by the Grupo de Neurociencias de Antioquia in clinical and genetic studies of ADHD in the Paisa genetic isolate.(Palacio et al., 2004) ADHD diagnosis were performed by two experienced neuropsychologists (PP-R and JA-L), who were trained by a Child Psychiatrist (DPA) from the Grupo de Neurociencias de Antioquia until a $\kappa$ concordance coefficient $>0.9$ was reached for ADHD, ODD and CD diagnoses, and $\kappa>0.75$ for other psychiatric diagnosis of the A criterion in the DSM-IV. The DICA-IV is highly reliable for each diagnostic category (Crobach's $\alpha>0.75$ ) as it has questions, counter questions, validation questions and skip questions regarding every symptom of each criterion in every diagnostic category, in addition to a series of standardised examples in each category, specially designed to determine burden criteria. Following the C criteria of DSM-IV, ADHD symptoms in children and adolescents were evaluated by 
ADHD endophenotypes in a Caribbean Community

110

111

112

113

114

115

116

117

118

119

120

121

122

123

124

125

126

127

128

129

130

their parents and teachers using the ADHD diagnosis was Colombian version of the Behavioural Assessment System for Children (BASC),(Pineda, Kamphaus, et al., 1999) and the ADHD checklist.(APA, 2000; DSM-IV, 2002)

\section{Neurological evaluation}

Anamnesis of personal and familiar pathological events was assessed using a neurological interview, which included prenatal, perinatal, childhood and language anomalies. First, mothers accompanied children during the neurological interview to facilitate the interaction with the examiner during the physical/neurological evaluation. Next, information about child's behaviour at home and at other scenarios (social events, parties, birthdays, etc.) is obtained from the mother. Subsequently, a new evaluation involving both parents is performed; information about parents' behaviour is obtained from the child's grandparents by telephonic interview to retrospectively assess parents' hyperactivity, inattention and impulsivity symptoms. Finally, a physical examination of senses, joints and cardiopulmonary, digestive, reproductive and nervous systems is further performed to every child, together with a neurological evaluation assessing cranial pairs, visual auditory syndromes, motorsensitive skills, muscular tone, reflexes and soft neurological signs.(Puentes Rozo, 2018)

\section{Neuropsychological tests}

We used the mental control subtests of an adapted version of the Wechsler Memory Scale $3^{\text {rd }}$ edition (WMS-III),(Wechsler, 2004) in addition to the Wechsler Intelligence Scale for Children $3^{\text {rd }}$ edition (WISC-III )(Wechsler, 1991) for children between 6-16 years old, the short-version of the Wechsler Adult Intelligence Scale $3^{\text {rd }}$ edition (WAIS-III),(Wechsler, 2003) the Trail Making Test parts A and B,(R. Reitan, 1958; R. M. Reitan, 1955; Ralph M Reitan \& Wolfson, 1985, 1995, 2004) visuoverbal 
ADHD endophenotypes in a Caribbean Community

131

132

133

134

135

136

137

138

139

140

141

142

143

144

145

146

147

148

149

150

151

memory test, the Rey-Osterrieth complex figure test (ROCFT) for copy and immediate recall,(Osterriech, 1944) the Token test, phonological and semantic fluency verbal tests,(Franke et al.) and the Wisconsin Card Sorting Test (WCST)(Heaton, Avitable, Grant, \& Matthews, 1999) and Stroop's words and colours test.(Golden, 1999) The full neuropsychological protocol is presented in Supplementary Table 2. The vocabulary, comprehension, arithmetic, digits and analogies subtests of the WISC-III/WAIS-III were used to assess verbal intelligence quotient (VIQ) and rule out mental retardation, and the incomplete figures, block design, and symbol search and puzzle tests, were used to assess the performance intelligence quotient.(Khodiyar et al.) A prorated full scale intelligence quotient (FSIQ) was estimated.(Wechsler, 2004)'(Wechsler, 1955)

Neurological and neuropsychological evaluations were performed at the Unit of Cognitive Neurosciences of the Caribbean Group of Neurosciences, Simon Bolivar University, Barranquilla, Colombia, in two sections of $\sim 1.5$ hours long each. To avoid any potential distraction or interference during the clinical evaluation period, participants were evaluated in a room with constant illumination, a temperature of $18^{\circ} \mathrm{C}$ and isolated from external noise.

Procedure

Eleven Spanish-speaking public schools located at disparate areas of Barranquilla, Colombia and its metropolitan area were visited. These schools provide educational services to population of medium (three to five) socioeconomic strata. This study was advertised in the Grupo Neurociencias del Caribe's website. Out of the schools visited, seven agreed to participate in our study. Once their participation was approved by delegated authorities, an informative meeting with teachers from each school to explain the objectives and dynamic of the study took place. Subsequently, teachers provided a complete 
ADHD endophenotypes in a Caribbean Community

152 list of children 6-11 years old (1st to 6th grades) attending their classes for the last six months, and

153 whom they would think could have any issue that may affect their academic performance or their 154 behaviour at school. Out of this list, we administered 845 checklist questionnaires(Pineda, Henao, et

155 al., 1999) to children, children's parents and teachers from these seven ascertained schools. A

156 georeferenced map showing the location of ascertained families is shown in Supplementary Figure 1.

157 Parents and other family members of children with scores higher than the $85^{\text {th }}$ percentile in the

158 checklist (this value is an indicator of an ADHD positive diagnosis)(Pineda, Henao, et al., 1999) were

159 further assessed and provided with all relevant information about the study. ADHD diagnosis in family

160 members was assessed using the DICA-IV interview and the DSM-IV criteria.(Pineda, Henao, et al., 161 1999) After reviewing both the clinical evaluation and the psychiatric interview, each individual's

162 diagnosis was discussed among a staff of well-experienced clinicians for confirmation. Our full 163 neuropsychological evaluation protocol is presented in Supplementary Table 2.

\section{Statistical analysis}

165 Measures of location and dispersion were employed to summarize continuous variables. Those variables meeting the assumptions of normality and homogeneity of variance were compared using the

$167 t$ test for independent samples or the nonparametric Mann-Whitney $U$ test otherwise. Normality and homogeneity of variance were tested with the Shapiro-Wilks and the Bartlett tests, respectively.

169 Uncorrected Cohen's $d$ was calculated to measure the effect size for all variables. To avoid the effect of 170 potential confounding variables such as age and gender, $P$-values were corrected using analysis of 
ADHD endophenotypes in a Caribbean Community

171 covariance (ANCOVA). Frequencies and proportions were estimated for categorical variables.

172 Categorical variables were compared using a $\chi^{2}$ test.

We used Advanced Recursive Partitioning Approach (ARPA) to construct a predictive tree-

based model of ADHD status in our cohort. Gender, age and potential cognitive endophenotypes were

used as predictors. ARPA offers fast solutions to reveal hidden complex substructures and provides

non-biased statistical analyses of high dimensional seemingly unrelated data, and is widely used in

177 predictive analyses as it accounts for non-linear hidden interactions better than alternative methods and

is independent of the type of data and of the data distribution type.(Rao, 1998) ARPA was applied

using the Classification and Regression Tree (CART),(L. Breiman, Friedman, Olshen, \& Stone, 1984)

Random Forest (L. Breiman, 2001; Satterfield, Cantwell, \& Satterfield) and TreeNet(Friedman, 1999)

modules implemented in the Salford Predictive Modeller® software suite (Salford Systems, San Diego,

CA, USA). A short description of CART, RF and TreeNet is provided in the Supplementary Material.

The final model was chosen based on a battery performance measures presented in Supplementary

184 Table 1.

\section{Heritability estimation}

186 To estimate heritability of neurological and neuropsychological variables in our sample, the ASSOC

187 module in the Statistical Analysis of Genetic Epidemiology (SAGE) software(Elston \& Gray-McGuire, 2004) Briefly, ASSOC evaluates the association between a continuous trait and one or more covariates

189 from pedigree data in the presence of familial correlations, and simultaneously estimates familial 
191 Parameters in the segregation model evaluated by ASSOC are estimated by maximum likelihood under 192 the assumption that parameters follow multivariate normality.(Bochud, 2012; Elston \& Gray-McGuire, 193 2004; R. C. Elston, J. M. Satagopan, \& S. Sun, 2012; Robert C Elston, Jaya M Satagopan, \& Shuying 194 Sun, 2012) 
ADHD endophenotypes in a Caribbean Community

\section{RESULTS}

\section{Subjects}

197 Four hundred and eight individuals (175 [43\%] females, 233 [57\%] males) from 120 nuclear families 198 were included in this study (Table 1). Of those, 236 (57.84\%) individuals were diagnosed as ADHD affected (161 [68.2\%] males, 75 [31.8\%] females; 105 [44.5\%] were diagnosed as ADHD inattentive, 32 [13.6\%] as ADHD hyperactive, and 99 [41.9\%] as ADHD combined type). No children or adults were under medication. Among affected individuals, the estimated male-to-female ratio was 2.146 $(95 \% \mathrm{CI}=1.65-2.85, P<0.001)$. As expected, the ADHD diagnosis distribution differed by gender $\left(\chi^{2}=\right.$ 27.16, degrees of freedom $\left.[\mathrm{df}]=1, P=1.87 \times 10^{-7}\right)$. The average age at diagnosis in the whole sample was $26.64 \pm 15.5$ (range: 6-60), and no statistically significant difference was found by gender (females: $25.34 \pm 16.77$ years; males: $28.37 \pm 13.5$ years; $W=18707, P=0.1537)$. The average family size in the 120 nuclear families was 3.4 \pm 0.64 individuals (range 3-6), with $80(66.7 \%)$ trios, 34 (28.3\%) quartets, four $(3.3 \%)$ families with five members and two (1.7\%) families with six members.(Pineda et al., 2016; Puentes Rozo, 2018) Furthermore, 32 (26.7\%) families had one affected individual, 63 (52.5\%) had two, $21(17.5 \%)$ families had three and $4(3.3 \%)$ families had four affected individuals; 88 (73.3\%) families had more than one member affected with ADHD. Analyses of the probands' relatives $(n=288)$ indicate that 120 of them are diagnosed with ADHD (77 males, 43 females, 41.6\%), with an age at diagnosis of $34.11 \pm 12.04$, which differed between males and females $(35.34 \pm 13.05$ vs. $32.83 \pm 10.78$, $213 P<0.0001)$. 
ADHD endophenotypes in a Caribbean Community

215

216 Neuropsychological differences between affected and unaffected individuals

217 We found statistically significant differences between ADHD affected and unaffected individuals after

controlling for age and gender in neurological and neuropsychological tasks measuring mental control,

219 visuospatial ability (i.e., ROCFT), visuoverbal memory, verbal fluency tasks (VFTs) by phonological

220 and semantic guidance, planning and abstraction (i.e., WCST), and intelligence (i.e., IQ in the WISC-

III and WAIS-III)(see Table 2 and Figure 1a). ADHD affected individuals had a lower score than unaffected individuals in the Total $9 / 9$ test $(4.44 \pm 2.54$ vs. $5.93 \pm 2.17, P=0.028)$, and in the numbers from 20 to 1 test $(2.13 \pm 0.99$ vs. $2.55 \pm 0.7, P=0.034)$ of the mental control subtest. Likewise, ADHD affected individuals had a lower score than unaffected individuals in the ROCF copy $(20.65 \pm 8.49$ vs. $26.31 \pm 6.5, P=0.002$ ) and ROCF evocation (immediate recall; $9.15 \pm 6.05$ vs. $13.38 \pm 6.16, P=2.4 \times 10^{-5}$ ) subtests, but not in the ROCF type $(2.64 \pm 1.53$ vs. $1.62 \pm 0.94, P=0.018)$ subtest or in the number of attempts needed to accomplish the visuoverbal memory test $(3.18 \pm 1.77$ vs. $2.7 \pm 0.91, P=0.027)$.

Conversely, unaffected individuals obtained an average score higher than affected individuals in the phonological VFTs $(12.34 \pm 9.84$ vs. $16.81 \pm 13.65, P=0.024)$, the $36 / 36$ Token test $(30.46 \pm 3.66$ vs. $32.04 \pm 4.21, P=0.001)$, and correct answers $(73.46 \pm 23.69$ vs. $80.9 \pm 20.42, P=0.014)$ of the WCST (i.e., planning and abstraction cognitive domain; see Supplementary Table 2). As expected, ADHD affected individuals performed poorer than ADHD unaffected individuals in the number of errors (53.6 \pm 23.21 vs. $46.58 \pm 20.34, P=0.031)$ and the number of correct answers at the conceptual level $(58.26 \pm 29.81$ vs. 
ADHD endophenotypes in a Caribbean Community

235

236

237

238

239

240

241

242

243

244

245

than unaffected individuals in the FSIQ of the WISC-III (children) and WAIS-III (adults) with low-tohigh effect sizes (Table 2 and Figure 1a).

\section{Heritability estimates}

Strong statistical evidence supporting genetics effects and hereditary transmission (measured by the heritability parameter, $h^{2}$ ) was found in several neuropsychological variables (tasks) used to clinically characterise our sample (Table 2 and Figure 1b). These variables include the score in the numbers 1 to $20\left(h^{2}=0.351, P=0.006\right)$ and alphabet errors $\left(h^{2}=0.546, P<0.00001\right)$ measuring mental control; the differed evocation at 20 test $\left(h^{2}=0.546, P<0.00001\right)$ assessing visuoverbal memory; the total number of errors $\left(h^{2}=0.765, P<0.00001\right)$ and perseverance $\left(h^{2}=0.546, P<0.00001\right)$ assessing phonological fluency; the total number of errors $\left(h^{2}=0.264, P=0.01\right)$ and perseverance $\left(h^{2}=0.669, P<0.00001\right)$ subtests assessing semantic verbal fluency; the Token $36 / 36$ test $\left(h^{2}=0.355, P=0.002\right)$; and all but the figure completion test $\left(h^{2}=0.176, P=0.094\right)$ in the WAIS subtests, indicating that most of the measures assessing FSIQ had significant heritability. Within the WAIS-III subtests, the highest heritability value was estimated in the vocabulary test $\left(h^{2}=0.452, P=1.7 \times 10^{-4}\right)$ and the minimum in the reverse digits test $\left(h^{2}=0.171, P=0.048\right)$. No significant genetic effects and hereditary transmission were found in neuropsychological variables assessing ROCF, continuous auditory execution or the verbal semantics (Table 2 and Figure 1b). Our results suggest both a simultaneous differential pattern in ADHD diagnosis and genetic effects and hereditary transmission (significant heritability) in the numbers from 20 to 1 mental control subtest, the 36/36 Token test and in most of the WAIS-III subtests (see Table 2 and Figure 1c).

\section{Predictive model for ADHD diagnosis}


ADHD endophenotypes in a Caribbean Community

256 Based on the performance measures presented in Supplementary Table 1, a five-level tree with seven

257 terminal nodes was derived by CART to differentiate ADHD affected individuals from unaffected in 258 our cohort of 120 nuclear families. Splitting nodes involved age at diagnosis, sex and traits 4 (numbers 259 from 20 to 1; Table 2), 44 (digits; Table 2), 45 (vocabulary; Table 2) and 47 (arithmetic; Table 2)

260 (Figure 2a). This predictive model was validated via RF and TreeNet, producing comparable results 261 (data not shown). Interestingly, these last four variables defining splitting nodes were also found to be 262 associated with ADHD and exhibited a significant heritability (that is, constitute endophenotypes; see 263 Table 2 and Figure 1c).

Out of the 408 individuals clinically assessed, 58\% of them were diagnosed as ADHD affected 265 and $42 \%$ as unaffected (node 1, Figure 2a). In the first split, children $<14$ years old have $87 \%$ chance of being diagnosed with ADHD regardless of gender (terminal node 3, 37\% of all sample), whilst those $267 \geq 14$ years have a 59\% change of being diagnosed as ADHD unaffected (node 2, 63\% of total sample). 268 Within this node, individuals with more than 12 points in trait 44 (digits; Table 2) have a $70 \%$ chance 269 of being classified as ADHD unaffected (node 4; 38\% of total sample), compared to 58\% of being 270 ADHD affected (node 5, 25\%). On the other hand, males with < 12 points in trait 44 (digits; Table 2) and $<14$ years old have a $74 \%$ (terminal node $11,12 \%$ of total sample) of being diagnosed as ADHD 272 affected. Likewise, females with $<12$ points in trait 44 (digits; Table 2), $<38$ points in trait 45

273 (vocabulary; Table 2) and $\geq 12$ points in trait 47 (arithmetic; Table 2 ) have a 91\% chance of being 274 diagnosed as ADHD affected (terminal node 43; 3\% of total sample) (Figure 2a; bottom). Finally, 275 females with $<38$ points in trait 45 (vocabulary; Table 2), $\geq 12$ points in trait 47 (arithmetic; Table 2) 
and $<1.5$ points in trait 4 (numbers from 20 to 1; Table 2) are classified as ADHD affected (terminal

277 node 85, 1\% of all sample) (Figure 2a; bottom).

279 for the CART strategy for the learn and test data sets. Although similar results were obtained with all strategies, CART performed better than RF and TreeNet (Supplementary Figure 2). The performance measures for the testing and learning data sets using the CART strategy are shown in Figure 2c (see also Supplementary Table 1). For the learning data set, the estimated AUC was 81.5 (95\%CI=77.685.3), with values of $81.4(95 \% \mathrm{CI}=77.5-85.0)$ for the classification rate, a sensitivity of 82.5 $(95 \% \mathrm{CI}=76.7-88.0)$, specificity of $80.5(95 \% \mathrm{CI}=75.3-85.5)$ and precision of $86.1(95 \% \mathrm{CI}=81.6-90.7)$, with overlapping 95\% CI in most of these measures for the learning data set based on 10-fold crossvalidation (Figure 2c). Further analysis indicated that this predictive model outperforms that including sex and gender only (Supplementary Figure 3). Altogether, these measures indicate substantial predictive power of these cognitive endophenotypes to differentiate ADHD affected from ADHD unaffected individuals. 
ADHD endophenotypes in a Caribbean Community

290

291

292

293

294

295

296

297

298

299

300

301

302

303

304

305

306

307

308

309

\section{DISCUSSION}

The purpose of this study was to define cognitive endophenotypes in a set of nuclear families ascertained from ADHD probands recruited from Barranquilla, Colombia. We characterized, by clinical neuropsychology methods, visuoconstructional skills, visuoverbal memory, language, executive function and intelligence domains. We found strong evidence that tasks of mental control, language, and intelligence meet the criteria for endophenotypes. Despite the well-known limitations of CART (that is, being a nonparametric technique, lacking the ability of forcing variables into the model, and high variance across samples),(L. Breiman et al., 1984; Gordon, 2013; Hayes, Usami, Jacobucci, \& McArdle, 2015; Ojha, 2018) these clinical variables accurately predict the ADHD status in this community (Figure 2 and Supplementary Figure 3). While we replicated endophenotypes described for other Colombian -and in general Latino- communities, there were new neuropsychological endophenotypes that perform as new major players in outlining ADHD and its neurobiological basis.

This new discovered endophenotypes might be specific, but the role they might play in other ADHD cohorts and studies in other communities will define their importance.

The findings in this study can be framed from two perspectives. Firstly, there is strong evidence supporting significant phenotypic differences between ADHD affected and unaffected individuals in the cognitive domains of mental control (total score and numbers from 20 to 1 of the mental control test), visuomotor skills (copy type, and scores of copy and evocation in ROCF), visuoverbal memory (number of trials in the visuoverbal memory test), phonological and semantic verbal fluency (total score of the verbal fluency test), as well as in language comprehension (Token test total score), 
ADHD endophenotypes in a Caribbean Community

310

311

312

313

314

315

316

317

318

319

320

321

322

323

324

325

326

327

328

329

abstraction and problem solving (number of correct responses, total errors and conceptual level

responses in the WCTS), comprehension and verbal reasoning (analogies, vocabulary, digits span and arithmetic, and comprehension subtests of the WISC-III/WAIS-III) and execution and perceptive reasoning (figure completion, block design, symbol search and objects assembly subtests of the WISCIII/WAIS-III)(Table 2 and Figure 1a). These results are not only consistent with other studies evaluating potential ADHD cognitive endophenotypes,(Peskin et al., 2015; Pineda et al., 2011) but also show how heterogeneous the ADHD phenotype is. In the mid-to-long term, these phenotypic differences might allow researchers to dissect the spectrum of cognitive and behavioural phenotypes in ADHD,(Cervantes-Henríquez, Acosta-López, Aguirre-Acevedo, Pineda-Álvarez, \& Puentes Rozo, 2008; Puentes, 2009; Puentes-Rozo, Barcelo-Martinez, \& Pineda, 2008) and contribute to the better understanding of the aetiology, subtypes and severity of this neuropsychiatric condition.(E. J. SonugaBarke, Dalen, Daley, \& Remington, 2002)

Secondly, we also identified statistically significant heritability indexes in the domains of mental control (numbers from 20 to 1 and abecedary errors), visuoverbal memory (differed evocation at 20), phonological and semantic verbal fluency (total errors and perseverance), language comprehension (Token test), verbal comprehension (vocabulary, analogies, arithmetic and digits span subtests of the WISC-III/WAIS-III) and execution (incomplete figures and objects assembly subtests of the WISCIII/WAIS-III) (Table 2 and Figure 1b). Although these findings are closely related to previous findings,(Doyle et al., 2005; Peskin et al., 2015; Pineda et al., 2011; Pineda et al., 2007; Rommelse, 2008; Rommelse et al., 2008) and provide supporting evidence regarding the genetic component of 
ADHD endophenotypes in a Caribbean Community

330 ADHD and how the offspring from parents affected with ADHD inherit this condition(Ramos-Quiroga,

331 Ribases-Haro, Bosch-Munso, Cormand-Rifa, \& Casas, 2007), only the domains of attention, tasks of verbal comprehension and some tasks of the execution scale in this Caribbean community are similar to the findings in the Paisa genetic isolate,(Pineda et al., 2011; Pineda et al., 2007) and those of a recent study in the Central Valley of Costa Rica,(Peskin et al., 2015) which reported high heritability values for attention and verbal IQ. In this study we found that verbal comprehension tasks, but verbal IQ, are highly heritable. It is intriguing how closely related the findings in the Paisa and this Costa Rican communities are compared to those in our Caribbean families, and that, unlike endophenotypes that were highly heritable in our sample, only two symptoms of the DSM-IV were so (Supplementary Table 3). This latter result supports the hypothesis that symptoms are not sufficient to determine genetic effects and hereditary transmission in ADHD, and that other approaches are needed.(Acosta et al., 2011) not the IQ were found to be potential endophenotypes suggests the existence of different IQ profiles among ADHD subtypes,(Pennington, 2006; Sonuga-Barke, Bitsakou, \& Thompson, 2010; E. J. Sonuga-Barke et al., 2002; E. J. Sonuga-Barke et al., 2008) and a potential association mainly with attention as a processing system, with temporal processing(Castellanos \& Tannock, 2002)and with working memory, thus interfiring with the normal learning processes and limiting the ability of individuals to easily adapt to the environment. In this sense, intelligence may not be critically compromised but diminished due to the aforementioned difficulties, and lead to learning disorders 
ADHD endophenotypes in a Caribbean Community

350 (Castellanos \& Tannock, 2002; Willcutt, Doyle, Nigg, Faraone, \& Pennington, 2005). Temporal-

351 processing and working memory deficits are associated with ADHD,(Castellanos \& Tannock, 2002)

352 which may partially explain why some attention and working memory tasks and not IQ resulted to be

353 potential endophenotypes in our sample. Tulsky, Saklofske \& Zhu(Tulsky, Saklofske, \& Zhu, 2003)

354 suggest that the IQ can be determined not only by cognitive aspects, but also by other motivational

355 factors. Thus, difficulties in attention and working memory are related to the cognitive and academic

356 impairment cluster observed in individuals with severe inattention than in individuals with

357 hyperactivity/impulsivity,(Castellanos \& Tannock, 2002) which is consistent with the inattention

358 profile of our sample.

359 Although genetic factors are implicated in the aetiology of ADHD and its comorbidities,(Acosta

et al., 2011; Arcos-Burgos et al., 2002; Arcos-Burgos et al., 2010; Jain et al., 2011; Palacio et al., 2004)

environmental, epigenetic, cultural and educational factors may offer an explanation about the

heterogeneity of the disorder.(Acosta et al., 2004) The fact that the number of endophenotypes

compromising several cognitive domains in our sample is considerably less than the phenotypes

evaluated (Table 2), puts us one step closer to genetic factors explaining ADHD variability.(Doyle et

al., 2005) Studying distinctive ADHD profiles, such that the inattentive type in our sample, may

potentially lead to the identification of genetic factors and physiopathological processes underlying

ADHD. However, it is important to acknowledge that, given the multifactorial nature of ADHD, our approach of comparing cognitive impairments in individuals with ADHD to impairments in unaffected relatives is limited. As a complementary approach, we conducted a factor analysis and studied the 
ADHD endophenotypes in a Caribbean Community

370

371

372

373

374

375

376

377

378

379

380

381

382

383

384

385

387

388

389

heritability of the derived factors (Supplementary Table 4 and Supplementary Figure 4). Interestingly, only factors constructed from phonetic fluency tasks, semantic verbal fluency, WCST and WISCIII/WAIS-III were found to be heritable.

Finding that some tasks of the WISC test were found to be heritable (Table 2 and Figure 1b) is consistent with the postulate that individuals having a family history of ADHD increases susceptibility to develop the condition as well as presenting major social and vocational difficulties than individuals with no family history.(Arcos-Burgos et al., 2002; Bochud, 2012; Faraone et al., 1993; Lopera et al., 1999; Lopez-Campo, Gomez-Betancur, Aguirre-Acevedo, Puerta, \& Pineda, 2005; Peskin et al., 2015; Pineda et al., 2011; Willcutt et al., 2005) We found significant heritability values in sustained visual attention, speed of information processing and resolution of visuospatial subtests of the Wechsler scale that might be used in genetic research of ADHD (i.e., fine-mapping and genome-wide linkage and associaton studies) as efficient phenotypic indicators. Following this approach, new neurobiological and genetic markers for ADHD can be defined and subsequently increase the power to detect genetic loci conferring susceptibility to the disorder.(Mastronardi et al., 2016)

The importance of our findings can be summarised as follows. First, the study was performed in a sample of 120 nuclear families from the metropolitan area of Barranquilla, Colombia, with at least one individual affected with ADHD. These families have been clinically characterised using extensive neuropsychological batteries during the last five years,(Pineda et al., 2016; Puentes Rozo, 2018) and constitute, to the best of our knowledge, the largest collection of nuclear families with ADHD in South America today. Because of their structure and admixture composition ( $63 \%$ African descendants is 
390 with a vast Amerindian contribution),(Barragán Duarte) these families constitute a powerful resource 391 for genetic studies of ADHD. Second, this is one of few studies examining the heritability of cognitive 392 measures as probable endophenotypes(Kuntsi et al., 2010) and might be useful to support future 393 molecular studies aiming to uncover the final causes of ADHD. Future studies will include conducting 394 linkage and association genetic analysis between common, rare and functional exomic variants to these 395 cognitive endophenotypes, and possibly deep sequencing of genes harbouring these variants in this set 396 of families. This will be crucial for accurate diagnostic, treatment, improve long-term outcomes and for 397 outlining public health policies.(Arango-Dávila, Rojas, \& Moreno, 2008; Posada, 2013) 
ADHD endophenotypes in a Caribbean Community

398

399

400

401

402

403

404

405

406

407

408

409

410

411

412

413

414

415

416

\section{Acknowledgements}

We express our highest appreciation to all families enrolled in this study. This study was financed by COLCIENCIAS, project “Fenotipos Complejos y Endofenotipos del Trastorno por Déficit de Atención e Hiperactividad y su Asociación con Genes Mayores y de Susceptibilidad”, grant 1253-5453-1644, contract RC 384-2011 conferred to Grupo de Neurociencias del Caribe, Universidad Simón Bolívar, Barranquilla. MLC-H, JAL and EM-S are doctoral students at Universidad del Norte, Barranquilla, Colombia, Universidad Maimónides in Buenos Aires, Argentina and Universidad De Flores in Buenos Aires, Argentina. Some of this work is to be presented in partial fulfilment of the requirements for the $\mathrm{PhD}$ degree. The sponsor of the study has no role in the study design, data collection, data analysis, data interpretation, or writing of the paper. MLC-H, JAL, JIV and PPR have full access to all the data in the study and are responsible for submitting this work for publication.

\section{Compliance with Ethical Standards}

The authors assert that all procedures contributing to this work have been performed in accordance with the ethical standards laid down in the 1964 Declaration of Helsinki and its later amendments. The views and opinions expressed in this article are those of the authors and should not be construed to represent the views of any of the sponsoring organizations, agencies, or governments.

Conflict of interest

None of the authors of this paper has a financial or personal relationship with other people or organizations that could inappropriately influence or bias the content of the paper. 
417 TABLES

418 Table 1. Demographic characteristics of 408 individuals included in this study.

\begin{tabular}{lccccc}
\hline & Affected & Unaffected & Statistic index & $P$ & Effect Size \\
& $n=236$ & $n=172$ & & & \\
Gender & Frequency (\%) & Frequency (\%) & $\chi^{2}$ & & \\
Male & $161(68.22)$ & $72(41.86)$ & 27.156 & $<0.00001$ & \\
Female & $75(31.78)$ & $100(58.14)$ & & & \\
& & & & & \\
& Mean (SD) & Mean (SD) & Mann-Whitney's $U$ & & \\
Age & $21.14(12.15)$ & $34.19(15.4)$ & 29746 & $<0.0001$ & 0.941 \\
\hline
\end{tabular}


420 Table 2. Performance on neurological and neuropsychological tasks of 408 individuals from the 421 Colombian Caribbean.

\begin{tabular}{|c|c|c|c|c|c|c|c|}
\hline \multirow{2}{*}{ \# } & \multirow{2}{*}{ Task } & \multirow{2}{*}{$\begin{array}{l}\text { Affected } \\
(n=236)\end{array}$} & \multirow{2}{*}{$\begin{array}{l}\text { Unaffected } \\
\qquad(n=172)\end{array}$} & \multirow{2}{*}{$d$} & \multirow{2}{*}{$P$} & \multicolumn{2}{|c|}{ Heritability } \\
\hline & & & & & & $h^{2}(\mathrm{SE})$ & $P$ \\
\hline & Mental Control & Mean (SD) & Mean (SD) & & & & \\
\hline 1 & Total score $9 / 9$ & $4.44(2.54)$ & $5.93(2.17)$ & 0.624 & 0.028 & $0.182(0.117)$ & 0.059 \\
\hline 2 & Time - Numbers from 20 to 1 & $16.68(14.49)$ & $11.29(6.28)$ & 0.459 & 0.147 & $a$ & $a$ \\
\hline 3 & Errors - Numbers from 20 to 1 & $0.25(1.56)$ & $0.13(0.47)$ & 0.103 & 0.817 & $a$ & $a$ \\
\hline 4 & Score - Numbers from 20 to 1 & $2.13(0.99)$ & $2.55(0.7)$ & 0.483 & 0.034 & $0.351(0.138)$ & 0.006 \\
\hline 5 & Time - Abecedary & $15.14(15.78)$ & $10.73(9.18)$ & 0.329 & 0.420 & $a$ & $a$ \\
\hline 6 & Errors - Abecedary & $0.78(2.06)$ & $0.48(1.36)$ & 0.171 & 0.443 & $0.546(0.089)$ & $1.0 \times 10^{-7}$ \\
\hline 7 & Score - Abecedary & $1.43(1.37)$ & $2.12(1.23)$ & 0.525 & 0.192 & $a$ & $a$ \\
\hline 8 & Time - Counting & $29.49(24.42)$ & $22(12.18)$ & 0.371 & 0.054 & $a$ & $a$ \\
\hline 9 & Errors - Counting & $1.44(2.84)$ & $1.52(2.99)$ & 0.026 & 0.941 & $a$ & $a$ \\
\hline 10 & Score - Counting & $0.84(1.14)$ & $1.22(1.27)$ & 0.319 & 0.237 & $a$ & $a$ \\
\hline & $\begin{array}{l}\text { A Continuous Auditory } \\
\text { Performance Test }\end{array}$ & & & & & & \\
\hline 11 & Correct answers & $13.53(3.01)$ & $15.15(1.53)$ & 0.649 & 0.062 & $a$ & $a$ \\
\hline 12 & Omissions & $2.32(2.8)$ & $0.85(1.53)$ & 0.626 & 0.083 & $a$ & $a$ \\
\hline 13 & Comissions & $1.94(2.03)$ & $1.22(1.59)$ & 0.385 & 0.246 & $a$ & $a$ \\
\hline & Rey-Osterrieth Complex Figure & & & & & & \\
\hline 14 & Copy (type) & $2.64(1.53)$ & $1.62(0.94)$ & 0.770 & 0.018 & $0.172(0.119)$ & 0.075 \\
\hline 15 & Copy (time) & $192.02(85.41)$ & $165.08(88.97)$ & 0.310 & 0.855 & $a$ & $a$ \\
\hline 16 & Copy (score) & $20.65(8.49)$ & $26.31(6.5)$ & 0.734 & 0.002 & $0.142(0.137)$ & 0.150 \\
\hline 17 & Evocation (time) & $115.81(53.56)$ & $129.66(56.92)$ & 0.252 & 0.058 & $a$ & $a$ \\
\hline 18 & Evoction (score) & $9.15(6.05)$ & $13.38(6.16)$ & 0.694 & $2.4 \times 10^{-5}$ & $0.185(0.115)$ & 0.055 \\
\hline & Visuoverbal Memory & & & & & & \\
\hline 19 & Initial volume & $6.44(1.64)$ & $6.66(1.41)$ & 0.142 & 0.123 & $0.141(0.113)$ & 0.105 \\
\hline 20 & Maximum volume 10/10 & $9.98(0.16)$ & $9.91(0.81)$ & 0.131 & 0.469 & $a$ & $a$ \\
\hline 21 & Number of trials & $3.21(1.69)$ & $2.81(1.09)$ & 0.275 & 0.027 & $0.065(0.109)$ & 0.274 \\
\hline 22 & Organizational index & $0.64(0.35)$ & $0.79(0.77)$ & 0.267 & 0.115 & $a$ & $a$ \\
\hline 23 & Differed evocation at 20 & $8.67(1.82)$ & $9.44(1.32)$ & 0.478 & 0.063 & $0.773(0.064)$ & $1.0 \times 10^{-7}$ \\
\hline & Phonetic Fluency Tasks & & & & & & \\
\hline
\end{tabular}




\begin{tabular}{|c|c|c|c|c|c|c|c|}
\hline 24 & Total score & $16.07(14.02)$ & 24.15 (17.99) & 0.511 & 0.024 & $a$ & $a$ \\
\hline 25 & Total errors & $2.57(3.06)$ & $2.76(2.99)$ & 0.065 & 0.466 & $0.765(0.050)$ & $1.0 \times 10^{-7}$ \\
\hline 26 & Missing categories & $11.6(13.03)$ & $13.53(16.09)$ & 0.134 & 0.768 & $a$ & $a$ \\
\hline \multirow[t]{2}{*}{27} & Perseverance & $0.92(1.53)$ & $1.18(1.39)$ & 0.177 & 0.418 & $0.653(0.079)$ & $1.0 \times 10^{-7}$ \\
\hline & Semantic Verbal Fluency Test & & & & & & \\
\hline 28 & Total score & $18.28(15.27)$ & $24.84(18.4)$ & 0.394 & 0.032 & $a$ & $a$ \\
\hline 29 & Total errors & $1.44(1.66)$ & $1.49(1.58)$ & 0.033 & 0.362 & $0.264(0.115)$ & 0.011 \\
\hline 30 & Missing categories & $22.8(36.52)$ & $18.55(28.52)$ & 0.128 & 0.305 & $a$ & $a$ \\
\hline 31 & Perseverance & $0.8(1.36)$ & $0.81(1.26)$ & 0.013 & 0.640 & $0.669(0.057)$ & $1.0 \times 10^{-7}$ \\
\hline \multirow[t]{2}{*}{32} & Token Test $36 / 36$ & $31.36(3.8)$ & $33.51(2.68)$ & 0.637 & 0.001 & $0.355(0.124)$ & 0.002 \\
\hline & Wisconsin Card Sorting Test & & & & & & \\
\hline 33 & Correct responses & $73.46(23.69)$ & $80.9(20.42)$ & 0.333 & 0.014 & $a$ & $a$ \\
\hline 34 & Total errors & $53.6(23.21)$ & $46.58(20.34)$ & 0.318 & 0.031 & $a$ & $a$ \\
\hline 35 & Nonperseverative errors & $29.6(20.17)$ & $24.05(15.64)$ & 0.302 & 0.073 & $a$ & $a$ \\
\hline 36 & Perseverative errors & $25.15(22.58)$ & $23.24(13.33)$ & 0.100 & 0.234 & $a$ & $a$ \\
\hline 37 & Categories & $5.26(18.6)$ & $4.89(2.92)$ & 0.026 & 0.174 & $a$ & $a$ \\
\hline 38 & Perseverative errors $(\%)$ & $21.41(33.89)$ & $19.43(15.05)$ & 0.072 & 0.885 & $a$ & $a$ \\
\hline 39 & Conceptual level responses & $58.26(29.81)$ & $66.56(27.4)$ & 0.288 & 0.044 & $a$ & $a$ \\
\hline 40 & Conceptual level responses (\%) & $46.8(23.67)$ & $53.01(20.91)$ & 0.276 & 0.083 & $a$ & $a$ \\
\hline \multirow[t]{2}{*}{41} & Failures to keep the principle & $1.43(1.52)$ & $1.39(1.28)$ & 0.028 & 0.832 & $0.138(0.107)$ & 0.099 \\
\hline & WISC-III and WAIS-III subtests & & & & & & \\
\hline 42 & Digit Span Total - Forward & $6.84(1.73)$ & $7.8(1.92)$ & 0.526 & $3.7 \times 10^{-4}$ & $0.492(0.107)$ & $1.0 \times 10^{-5}$ \\
\hline 43 & Digit Span Total - Backward & $4.53(1.88)$ & $5.24(1.87)$ & 0.375 & 0.001 & $0.171(0.102)$ & 0.048 \\
\hline 44 & Total & $11.32(3.06)$ & $13.12(3.33)$ & 0.564 & $1.6 \times 10^{-5}$ & $0.416(0.109)$ & $6.8 \times 10^{-5}$ \\
\hline 45 & Vocabulary & $28.28(10.63)$ & 35.51 (10.99) & 0.670 & 0.005 & $0.452(0.126)$ & $1.7 \times 10^{-4}$ \\
\hline 46 & Comprehension & $17.75(6.27)$ & $21.01(5.88)$ & 0.533 & 0.019 & $0.210(0.107)$ & 0.025 \\
\hline 47 & Arithmetic & $12.94(4.52)$ & $12.87(3.87)$ & 0.016 & 0.007 & $0.365(0.116)$ & 0.001 \\
\hline 48 & Similarities & $16.16(6.98)$ & $20.55(5.89)$ & 0.671 & 0.002 & $0.366(0.130)$ & 0.003 \\
\hline 49 & Figure completion & $18.81(4.86)$ & $20.58(3.45)$ & 0.410 & 0.036 & $0.235(0.133)$ & 0.039 \\
\hline 50 & Block design & $30.89(14.28)$ & $37.99(12.86)$ & 0.518 & $1.8 \times 10^{-4}$ & $a$ & $a$ \\
\hline 51 & Symbol search & $21.45(8.73)$ & $25.96(8.81)$ & 0.514 & 0.015 & $0.176(0.133)$ & 0.094 \\
\hline \multirow[t]{2}{*}{52} & Objects assembly & $25.56(8.8)$ & $29.92(9.13)$ & 0.488 & 0.012 & $0.323(0.132)$ & 0.007 \\
\hline & Intelligence Quotient (IQ) & & & & & & \\
\hline 53 & Verbal & $98.51(16.81)$ & $97.44(12.33)$ & 0.071 & 0.078 & $a$ & $a$ \\
\hline
\end{tabular}


54 Performance

$100.98(16.69) \quad 101.42(11.45) \quad 0.030 \quad 0.128$

55 Full scale

$99.15(16.85) \quad 98.86(12.14) \quad 0.019 \quad 0.040$

$422{ }^{a}$ Parameter could not be maximized in SAGE. ${ }^{b}$ Corrected for gender and age. ${ }^{c}$ Corrected for ADHD

423 status, gender and age. $d$ : Cohen's effect size; $h^{2}$ : heritability estimated value; SE: Standard error.

424 Potential endophenotypes are highlighted in blue. $P$-values $<0.05$ are shown in bold. Task numbers

425 highlighted in red are included in the predictive model for ADHD status (see Figure 2). 
ADHD endophenotypes in a Caribbean Community

426

427

428

429

430

431

432

433

434

435

436

437

438

439

440

441

FIGURE LEGENDS

Figure 1. Neurological and neuropsychological where (a) ADHD affected individuals differed from unaffected individuals; (b) genetic effects and hereditary transmission are present; and (c) fulfill the requirements to be considered as potential endophenotypes. Displayed numbers correspond to task \# in Table 2.

Figure 2. Classification tree for predicting ADHD status in individuals from the Colombian Caribbean. Numbers within white squares represent the node number, the first line corresponds to the most frequent class (0: unaffected; 1: ADHD affected), the second line to the probability of each class within the node, and the third line to the percentage of the total sample size $(n=408)$ within each node. Nodes where ADHD affected individuals are more likely to be classified are shown in blue. (b) Variable importance (left) and ROC curve (Ando, Ono, \& Wright) for the CART strategy. Displayed numbers correspond to task \# in Table 2. (c) Performance measures for the learning (blue) and test (pink) data sets. AUC: Area under the curve; CART: Classification and regression tree; CI: confidence interval; CR: Classification rate; ROC: Receiver operating characteristic. 
ADHD endophenotypes in a Caribbean Community

442

443

444

445

446

447

448

449

450

451

452

453

454

455

456

457

458

459

460

461

462

463

464

465

466

467

468

469

470

471

472

473

474

475

476

477

478

479

\section{REFERENCES}

Acosta, M. T., Arcos-Burgos, M., \& Muenke, M. (2004). Attention deficit/hyperactivity disorder (ADHD): complex phenotype, simple genotype? Genet Med, 6(1), 1-15. doi:10.1097/01.GIM.0000110413.07490.0B

Acosta, M. T., Velez, J. I., Bustamante, M. L., Balog, J. Z., Arco-Burgos, M., \& Muenke, M. (2011). A two-locus genetic interaction between LPHN3 and 11q predicts ADHD severity and long-term outcome. Translational Psychiatry.

Acosta-Lopez, J., Cervantes-Henriquez, M., L., Jiménez-Figueroa, G., M., N., M., S., \& P., P. (2013). Uso de una escala comportamental Wender Utah para evaluar en retrospectiva trastorno de atención-hiperactividad en adultos de la ciudad de Barranquilla. La Revista Universidad y Salud, , 15, 45-61.

Acosta-López, J., Cervantes-Henríquez, M., Sánchez-Rojas, M., Núñez-Barragán, M., Puentes Rozo, P., Aguirre-Acevedo, D., \& Pineda, D. (2010). Alteraciones del Control Inhibitorio Conductual en Niños de 6 A 11 Años Con TDAH Familiar de Barranquilla. psicogente, 13(24), 274-291.

Ando, J., Ono, Y., \& Wright, M. J. (2001). Genetic structure of spatial and verbal working memory. Behav Genet, 31(6), 615-624.

APA. (2000). Diagnostic and statistical manual of mental disorders (DSM). Washington, DC: American psychiatric association, 4th ed.,.

Arango-Dávila, C., A., Rojas, J., \& Moreno, M. (2008). Análisis de los aspectos asociados a la enfermedad mental en Colombia y la formación en psiquiatría. Revista colombiana de psiquiatría, 37(4), 538-563.

Arcos-Burgos, M., Castellanos, F. X., Lopera, F., Pineda, D., Palacio, J. D., Garcia, M., .. . Muenke, M. (2002). Attention-deficit/hyperactivity disorder (ADHD): feasibility of linkage analysis in a genetic isolate using extended and multigenerational pedigrees. Clin Genet, 61(5), 335-343. doi:cge610503 [pii]

Arcos-Burgos, M., Jain, M., Acosta, M. T., Shively, S., Stanescu, H., Wallis, D., . . Muenke, M. (2010). A common variant of the latrophilin 3 gene, LPHN3, confers susceptibility to ADHD and predicts effectiveness of stimulant medication. Molecular psychiatry, 15(11), 1053-1066. doi:mp20106 [pii]10.1038/mp.2010.6

Arcos-Burgos, M., \& Muenke, M. (2002). Genetics of population isolates. Clinical genetics, 61(4), 233-247.

Barkley. (1997). Attention-deficit/hyperactivity disorder, self-regulation, and time: toward a more comprehensive theory. J Dev Behav Pediatr, 18(4), 271-279.

Barragán Duarte, J. L. Mapa genético de los colombianos [Colombian genetic map]. Retrieved from http://historico.unperiodico.unal.edu.co/ediciones/105/15.html

Barragán-Duarte, J. L. (2007). Mapa genético de los colombianos. UN Periódico, 105.

Biederman, J., \& Faraone, S. V. (2005). Attention-deficit hyperactivity disorder. Lancet, 366(9481), 237-248. doi:10.1016/S0140-6736(05)66915-2 
ADHD endophenotypes in a Caribbean Community

480

481

482

483

484

485

486

487

488

489

490

491

492

493

494

495

496

497

498

499

500

501

502

503

504

505

506

507

508

509

510

511

512

513

514

515

516

517

518

519

Bochud, M. (2012). Estimating heritability from nuclear family and pedigree data. Statistical Human Genetics: Methods and Protocols, 171-186.

Breiman, L. (2001). Random Forests. In R. E. Schapire (Ed.), Machine Learning (Vol. 45, pp. 5-32). Statistics Department, University of California, Berkeley, CA 94720: Kluwer Academic Publishers. Manufactured in The Netherlands.

Breiman, L., Friedman, J. H., Olshen, R. A., \& Stone, C. H. (1984). Classification and Regression Trees. Belmont, CA: Wadsworth International Group, Inc.

Brotman, M. A., Guyer, A. E., Lawson, E. S., Horsey, S. E., Rich, B. A., Dickstein, D. P., . . . Leibenluft, E. (2008). Facial emotion labeling deficits in children and adolescents at risk for bipolar disorder. Am J Psychiatry, 165(3), 385-389. doi:10.1176/appi.ajp.2007.06122050

Bukstein, O. G. (2012). Attention deficit hyperactivity disorder and substance use disorders. Current topics in behavioral neurosciences, 9, 145-172.doi:10.1007/7854_2011_148

Cannon, T. D., Gasperoni, T. L., van Erp, T. G., \& Rosso, I. M. (2001). Quantitative neural indicators of liability to schizophrenia: implications for molecular genetic studies. Am J Med Genet, 105(1), 16-19.

Castellanos, F. X., \& Tannock, R. (2002). Neuroscience of attention-deficit/hyperactivity disorder: the search for endophenotypes. Nat Rev Neurosci, 3(8), 617-628. doi:10.1038/nrn896

Cervantes-Henríquez, M., Acosta-López, J., Aguirre-Acevedo, D., Pineda-Álvarez, D., \& Puentes Rozo, P. (2008). Fenotipo comportamental evaluado con una escala multidimensional de la conducta en niños y adolescentes de 30 familias con trastorno de atención-hiperactividad. Acta Neurol Colomb, 24, 53-62.

Doyle, A. E., Faraone, S. V., Seidman, L. J., Willcutt, E. G., Nigg, J. T., Waldman, I. D., . . Biederman, J. (2005). Are endophenotypes based on measures of executive functions useful for molecular genetic studies of ADHD? J Child Psychol Psychiatry, 46(7), 774-803. doi:10.1111/j.1469-7610.2005.01476.x

DSM-IV. (2002). Manual Diagnóstico y Estadístico de los Trastornos Mentales: Texto Revisado: Masson.

Elston, R. C., \& Gray-McGuire, C. (2004). A review of the 'Statistical Analysis for Genetic Epidemiology' (S.A.G.E.) software package. Hum Genomics, 1(6), 456-459.

Elston, R. C., Satagopan, J. M., \& Sun, S. (2012). Genetic terminology. Methods Mol Biol, 850, 1-9. doi:10.1007/978-1-61779-555-8_1

Elston, R. C., Satagopan, J. M., \& Sun, S. (2012). Statistical human genetics: Humana Press;.

Faraone, S. V., Biederman, J., Lehman, B. K., Keenan, K., Norman, D., Seidman, L. J., . . Chen, W. J. (1993). Evidence for the independent familial transmission of attention deficit hyperactivity disorder and learning disabilities: results from a family genetic study. Am J Psychiatry, 150(6), 891-895. doi:10.1176/ajp.150.6.891

Flint, J., \& Munafo, M. R. (2007). The endophenotype concept in psychiatric genetics. Psychol Med, 37(2), 163-180. doi:10.1017/S0033291706008750

Franke, B., Vasquez, A. A., Johansson, S., Hoogman, M., Romanos, J., Boreatti-Hummer, A., . . Reif, A. (2010). Multicenter analysis of the SLC6A3/DAT1 VNTR haplotype in persistent ADHD 
ADHD endophenotypes in a Caribbean Community

suggests differential involvement of the gene in childhood and persistent ADHD. Neuropsychopharmacology, 35(3), 656-664. doi:10.1038/npp.2009.170

Friedman, J. H. (1999). Greedy Function Approximation: a Gradient Boosting Machine. Retrieved from Stanford:

Golden, C. J. (1999). Stroop Test de Colores y Palabras: Manual de aplicación (M. TEA Ediciones, España Ed.).

Gordon, L. (2013). Using Classification and Regression Trees (CART) in SAS® Enterprise Miner For Applications in Public Health. Paper presented at the SAS Global Forum 2013: Data Mining and Text Analytics.

Gottesman, II, \& Gould, T. D. (2003). The endophenotype concept in psychiatry: etymology and strategic intentions. Am J Psychiatry, 160(4), 636-645. doi:10.1176/appi.ajp.160.4.636

Gottesman, II, \& Shields, J. (1967). A polygenic theory of schizophrenia. Proc Natl Acad Sci U S A, 58(1), 199-205.

Hayes, T., Usami, S., Jacobucci, R., \& McArdle, J. J. (2015). Using Classification and Regression Trees (CART) and Random Forests to Analyze Attrition: Results From Two Simulations. Psychol Aging, 30(4), 911-929. doi:https://dx.doi.org/10.1037\%2Fpag0000046

Heaton, R. K., Avitable, N., Grant, I., \& Matthews, C. G. (1999). Further crossvalidation of regressionbased neuropsychological norms with an update for the Boston Naming Test. J Clin Exp Neuropsychol, 21(4), 572-582. doi:10.1076/jcen.21.4.572.882

Henriquez-Henriquez, M. P., Billeke, P., Henriquez, H., Zamorano, F. J., Rothhammer, F., \& Aboitiz, F. (2014). Intra-Individual Response Variability Assessed by Ex-Gaussian Analysis may be a New Endophenotype for Attention-Deficit/Hyperactivity Disorder. Front Psychiatry, 5, 197. doi:10.3389/fpsyt.2014.00197

Hwang-Gu, S. L., \& Gau, S. S. (2015). Interval timing deficits assessed by time reproduction dual tasks as cognitive endophenotypes for attention-deficit/hyperactivity disorder. PLoS One, 10(5), e0127157. doi:10.1371/journal.pone.0127157

Jain, M., Velez, J. I., Acosta, M. T., Palacio, L. G., Balog, J., Roessler, E., . . Muenke, M. (2011). A cooperative interaction between LPHN3 and 11q doubles the risk for ADHD. Molecular psychiatry. doi:10.1038/mp.2011.59

John, B., \& Lewis, K. R. (1966). Chromosome variability and geographic distribution in insects. Science, 152(3723), 711-721. doi:10.1126/science.152.3723.711

Khodiyar, V. K., Maltais, L. J., Ruef, B. J., Sneddon, K. M., Smith, J. R., Shimoyama, M., .. . Lovering, R. C. (2007). A revised nomenclature for the human and rodent alpha-tubulin gene family. Genomics, 90(2), 285-289. doi:10.1016/j.ygeno.2007.04.008

Kuntsi, J., Wood, A. C., Rijsdijk, F., Johnson, K. A., Andreou, P., Albrecht, B., . . Asherson, P. (2010). Separation of cognitive impairments in attention-deficit/hyperactivity disorder into 2 familial factors. Arch Gen Psychiatry, 67(11), 1159-1167. doi:10.1001/archgenpsychiatry.2010.139

Lee Gregory, M., Burton, V. J., Shapiro, B. K., Rowland, L. P., \& Coyle, J. T. (2015). Developmental Disabilities and Metabolic Disorders. In Neurobiology of Brain Disorders (pp. 18-41). 
ADHD endophenotypes in a Caribbean Community

560

561

562

563

564

565

566

567

568

569

570

571

572

573

574

575

576

577

578

579

580

581

582

583

584

585

586

587

588

589

590

591

592

593

594

595

596

597

Lopera, F., Palacio, L. G., Jimenez, I., Villegas, P., Puerta, I. C., Pineda, D., . . Arcos-Burgos, M. (1999). [Discrimination between genetic factors in attention deficit]. Rev Neurol, 28(7), 660664.

Lopez-Campo, G. X., Gomez-Betancur, L. A., Aguirre-Acevedo, D. C., Puerta, I. C., \& Pineda, D. A. (2005). [Attention and executive function tests components in attention deficit/hyperactivity children]. Rev Neurol, 40(6), 331-339.

Mastronardi, C. A., Pillai, E., Pineda, D. A., Martinez, A. F., Lopera, F., Velez, J. I., . . Arcos-Burgos, M. (2016). Linkage and association analysis of ADHD endophenotypes in extended and multigenerational pedigrees from a genetic isolate. Molecular psychiatry, 21(10), 1434-1440. doi:10.1038/mp.2015.172

Miller, G. A., \& Rockstroh, B. S. (2016). The Neurobiology of Schizophrenia. In (pp. 17-38).

Nigg, J. T. (2001). Is ADHD a disinhibitory disorder? Psychol Bull, 127(5), 571-598.

Ojha, A. K. (2018). Use a Classification and Regression Tree (CART) for Quick Data Insights. Retrieved from https://www.isixsigma.com/methodology/lean-methodology/use-aclassification-and-regression-tree-cart-for-quick-data-insights/

Osterriech, P. A. (1944). Le test de copie d'une figure complexe. Archives de Psychologie, 30, 206356.

Palacio, J. D., Castellanos, F. X., Pineda, D. A., Lopera, F., Arcos-Burgos, M., Quiroz, Y. T., . . . Muenke, M. (2004). Attention-deficit/hyperactivity disorder and comorbidities in 18 Paisa Colombian multigenerational families. J Am Acad Child Adolesc Psychiatry, 43(12), 15061515. doi:S0890-8567(09)61384-8 [pii]10.1097/01.chi.0000142279.79805.dc

Pelham, W. E., Jr., \& Fabiano, G. A. (2008). Evidence-based psychosocial treatments for attentiondeficit/hyperactivity disorder. Journal of clinical child and adolescent psychology: the official journal for the Society of Clinical Child and Adolescent Psychology, American Psychological Association, Division 53, 37(1), 184-214. doi:10.1080/15374410701818681

Pennington, B. F. (2006). From single to multiple deficit models of developmental disorders. Cognition, 101(2), 385-413. doi:10.1016/j.cognition.2006.04.008

Peskin, V. A., Ordonez, A., Mackin, R. S., Delucchi, K., Monge, S., McGough, J. J., . . Mathews, C. A. (2015). Neuropsychological and dimensional behavioral trait profiles in Costa Rican ADHD sib pairs: Potential intermediate phenotypes for genetic studies. Am J Med Genet B Neuropsychiatr Genet, 168B(4), 247-257. doi:10.1002/ajmg.b.32305

Pineda, D. A., Acosta-López, J., Cervantes-Henríquez, M. L., Jiménez-Figueroa, G., Sánchez-Rojas, M., Pineda-Alhucema, W., . . Puentes Rozo, P. J. (2016). Conglomerados de clases latentes en 408 miembros de 120 familias nucleares de Barranquilla con un caso índice afectado de trastorno de atencíon hiperactividad (TDAH). Acta Neurol Colomb, 32(4), 275-284.

Pineda, D. A., Henao, G. C., Puerta, I. C., Mejia, S. E., Gomez, L. F., Miranda, M. L., . . Murrelle, L. (1999). [The use of brief questionnaire in the diagnosis of attention deficit. Study group of the Manizales University Foundation]. Rev Neurol, 28(4), 365-372. 
ADHD endophenotypes in a Caribbean Community

598

599

600

601

602

603

604

605

606

607

608

609

610

611

612

613

614

615

616

617

618

619

620

621

622

623

624

625

626

627

628

629

630

631

632

633

634

635

636

Pineda, D. A., Kamphaus, R. W., Mora, O., Restrepo, M. A., Puerta, I. C., Palacio, L. G., .. . Holguin, J. A. (1999). [A system of multidimensional behavior assessment. A scale for parents of children from 6 to 11 years of age. Colombian version]. Rev Neurol, 28(7), 672-681.

Pineda, D. A., Lopera, F., Puerta, I. C., Trujillo-Orrego, N., Aguirre-Acevedo, D. C., Hincapie-Henao, L., . . Arcos-Burgos, M. (2011). Potential cognitive endophenotypes in multigenerational families: segregating ADHD from a genetic isolate. Atten Defic Hyperact Disord, 3(3), 291299. doi:10.1007/s12402-011-0061-3

Pineda, D. A., Palacio, L. G., Puerta, I. C., Merchan, V., Arango, C. P., Galvis, A. Y., . . ArcosBurgos, M. (2007). Environmental influences that affect attention deficit/hyperactivity disorder: study of a genetic isolate. Eur Child Adolesc Psychiatry, 16(5), 337-346. doi:10.1007/s00787007-0605-4

Pironti, V. A., Lai, M. C., Muller, U., Dodds, C. M., Suckling, J., Bullmore, E. T., \& Sahakian, B. J. (2014). Neuroanatomical abnormalities and cognitive impairments are shared by adults with attention-deficit/hyperactivity disorder and their unaffected first-degree relatives. Biol Psychiatry, 76(8), 639-647. doi:10.1016/j.biopsych.2013.09.025

Posada, J., A. (2013). La salud mental en Colombia. Biomédica, 33(4), 497-498.

Puentes, P. (2009). Neuropsicología de las funciones ejecutivas. Barranquilla, Colombia: Ediciones Universidad Simón Bolivar.[Links].

Puentes Rozo, P., Acosta-Lopez JE, Cervantes-Henriquez M, Martinez-Banfi,M, Lozano-Gutierrez, S, Jimenez -Figueroa, G, Pineda- Alhucema, W, Mejia-Segura, E, Zurbaran, MA, Zurek EE, Sanchez-Rojas M, Arcos-Burgos, M, Velez JI, Pineda, DA. (2018). Attention Deficit /Hyperactivity Disorder and Comorbidities in 120 Nuclear Families from a Caribbean Community (to be Submitted).

Puentes-Rozo, P. J., Barcelo-Martinez, E., \& Pineda, D. A. (2008). Behavioural and neuropsychological characteristics of children of both sexes, between 6 and 11 years of age, with attention deficit hyperactivity disorder]. Rev Neurol, 47(4), 175-184.

Ramos-Quiroga, J. A., Ribases-Haro, M., Bosch-Munso, R., Cormand-Rifa, B., \& Casas, M. (2007). [Genetic advances in attention deficit hyperactivity disorder]. Rev Neurol, 44 Suppl 3, S51-52.

Rao, D. C. (1998). CAT scans, PET scans, and genomic scans. Genetic epidemiology, 15(1), 1-18. doi:10.1002/(SICI)1098-2272(1998)15:1<1::AID-GEPI1>3.0.CO;2-B

Reich, W. (2000). Diagnostic interview for children and adolescents (DICA). J Am Acad Child Adolesc Psychiatry, 39(1), 59-66. doi:S0890-8567(09)66101-3 [pii]10.1097/00004583-20000100000017

Reitan, R. (1958). The validity of the trail making test as an indicator of organic brain damage.[8: 2716]. 1958. Perceptual and Motor skills.

Reitan, R. M. (1955). The relation of the trail making test to organic brain damage. J Consult Psychol, 19(5), 393-394.

Reitan, R. M., \& Wolfson, D. (1985). The Halstead-Reitan neuropsychological test battery: Theory and clinical interpretation (Vol. 4): Reitan Neuropsychology. 
ADHD endophenotypes in a Caribbean Community

637

638

639

640

641

642

643

644

645

646

647

648

649

650

651

652

653

654

655

656

657

658

659

660

661

662

663

664

665

666

667

668

669

670

671

672

673

674

675

676

677

Reitan, R. M., \& Wolfson, D. (1995). Category Test and Trail Making Test as measures of frontal lobe functions. The Clinical Neuropsychologist, 9(1), 50-56.

Reitan, R. M., \& Wolfson, D. (2004). The Trail Making Test as an initial screening procedure for neuropsychological impairment in older children. Archives of Clinical Neuropsychology, 19(2), 281-288.

Rhee, S. H., Waldman, I. D., Hay, D. A., \& Levy, F. (1999). Sex differences in genetic and environmental influences on DSM-III-R attention-deficit/hyperactivity disorder. J Abnorm Psychol, 108(1), 24-41.

Rommelse, N. N. (2008). Endophenotypes in the genetic research of ADHD over the last decade: have they lived up to their expectations? Expert Rev Neurother, 8(10), 1425-1429. doi:10.1586/14737175.8.10.1425

Rommelse, N. N., Arias-Vasquez, A., Altink, M. E., Buschgens, C. J., Fliers, E., Asherson, P., .. . Franke, B. (2008). Neuropsychological endophenotype approach to genome-wide linkage analysis identifies susceptibility loci for ADHD on 2q21.1 and 13q12.11. Am J Hum Genet, 83(1), 99-105. doi:10.1016/j.ajhg.2008.06.006

Satterfield, J. H., Cantwell, D. P., \& Satterfield, B. T. (1974). Pathophysiology of the hyperactive child syndrome. Arch Gen Psychiatry, 31(6), 839-844.

Sibley, M. H., Pelham, W. E., Jr., Molina, B. S., Gnagy, E. M., Waschbusch, D. A., Garefino, A. C., . . . Karch, K. M. (2012). Diagnosing ADHD in adolescence. Journal of consulting and clinical psychology, 80(1), 139-150. doi:10.1037/a0026577

Sonuga-Barke, Bitsakou, P., \& Thompson, M. (2010). Beyond the dual pathway model: evidence for the dissociation of timing, inhibitory, and delay-related impairments in attentiondeficit/hyperactivity disorder. J Am Acad Child Adolesc Psychiatry, 49(4), 345-355.

Sonuga-Barke, E. J., Dalen, L., Daley, D., \& Remington, B. (2002). Are planning, working memory, and inhibition associated with individual differences in preschool ADHD symptoms? Dev Neuropsychol, 21(3), 255-272. doi:10.1207/S15326942DN2103_3

Sonuga-Barke, E. J., Sergeant, J. A., Nigg, J., \& Willcutt, E. (2008). Executive dysfunction and delay aversion in attention deficit hyperactivity disorder: nosologic and diagnostic implications. Child Adolesc Psychiatr Clin N Am, 17(2), 367-384, ix. doi:10.1016/j.chc.2007.11.008

Tacchini, G., Coppola, M. T., Musazzi, A., Altamura, A. C., \& Invernizzi, G. (1994). [Multinational validation of the Composite International Diagnostic Interview (CIDI)]. Minerva Psichiatr, $35(2), 63-80$.

Tulsky, D. S., Saklofske, D. H., \& Zhu, J. (2003). Chapter 2 - Revising a Standard: An Evaluation of the Origin and Development of the WAIS-III. In Practical Resources for the Mental Health Professional (pp. 43-92): Academic Press.

Villalón, J. (2008). Colonias extranjeras en Barranquilla. Barranquilla, Colombia.

Visser, S., Bitsko, R., Danielson, M., \& Perou, R. (2010). Increasing Prevalence of Parent-Reported Attention-Deficit/Hyperactivity Disorder Among Children --- United States, 2003 and 2007. Mortality and Morbidity Weekly Report, 59, 1439-1443.

Walters, J. T., \& Owen, M. J. (2007). Endophenotypes in psychiatric genetics. Molecular psychiatry, 12(10), 886-890. doi:10.1038/sj.mp.4002068 
678

679

680

681

682

683

684

685

686

687

688

689

690

691

692

693

Wechsler, D. (1955). Wechsler Adult Intelligence Scale. New York: The Psychological Corporation Wechsler, D. (1991). Test de Inteligencia para niños WISC-III: PAIDOS, Buenos Aires.

Wechsler, D. (2003). Escala Wechsler de Inteligencia para adultos-III. $3^{\circ}$ edición: Manual Moderno, México.

Wechsler, D. (2004). Escala de memoria de Wechsler-III: Ediciones TEA, Madrid.

Willcutt, E. G., Betjemann, R. S., McGrath, L. M., Chhabildas, N. A., Olson, R. K., DeFries, J. C., \& Pennington, B. F. (2010). Etiology and neuropsychology of comorbidity between RD and ADHD: the case for multiple-deficit models. Cortex, 46(10), 1345-1361. doi:10.1016/j.cortex.2010.06.009

Willcutt, E. G., Doyle, A. E., Nigg, J. T., Faraone, S. V., \& Pennington, B. F. (2005). Validity of the executive function theory of attention-deficit/hyperactivity disorder: a meta-analytic review. Biol Psychiatry, 57(11), 1336-1346. doi:10.1016/j.biopsych.2005.02.006

Willcutt, E. G., Pennington, B. F., Duncan, L., Smith, S. D., Keenan, J. M., Wadsworth, S., . . Olson, R. K. (2010). Understanding the complex etiologies of developmental disorders: behavioral and molecular genetic approaches. J Dev Behav Pediatr, 31(7), 533-544.

doi:10.1097/DBP.0b013e3181ef42a1 